\title{
Brasilidades e Devir
}

Brazilities and Becoming

Brasilidades y Devenir

Guilherme Augusto Souza Prado

Universidade Federal do Piauí (UFDPar-CMRV), Parnaíba - PI, Brasil.

Márcio José de Araújo Costa

Universidade Federal do Maranhão (UFMA), São Luís - MA, Brasil.

Lançado recentemente em edição bilíngue pela editora $n-1$, o livro Brazuca negão e sebento é uma aventura e um convite do autor, o filósofo e professor francês J.-C. Goddard, de experimentação filosófico-literária com a condição brasileira. Tarefa tortuosa, na medida em que toma uma brasilidade conceitualmente indomesticável, impossível de ser abarcada ou apreendida como pontua Viveiros de Castro no prefácio do livro. Para nós, brasileiros, não deixa de ser incômodo, por um lado, e engraçado, por outro, ler mais um produto estrangeiro sobre nós mesmos.

O livro-experiência de Goddard é perpassado por uma visão que os brazucas veem muito entre os gringos, o de uma admiração-estupefação com a brasilidade, com nosso espírito, tão distinto do europeu. Por isso, esse conto intempestivo sobre o onirismo de um tal Bento, chamado Espinosa, não deixa de ser, para nós, uma provocação. E nós, brazucas, negões e sebentos, somos chamados a fazer uma resenha dessa experiência de pensamento tão brasileira, mas, ainda, muito gringa, muito estrangeira - embora nos seja estranho-familiar, por usar referências francesas, essa França colonialista tão sonhada e desejada por muitos de nós, acadêmicos brazucas pátria amada, idolatrada, salve, salve!!

A primeira impressão que um leitor brasileiro crítico tem dessa aventura intelectual, mais ainda dois anos depois de sua publicação e no contexto sócio-político que o Brasil vive nos últimos seis anos, que o francês, como se diz na tradução brasileira, "pirou na batatinha". Afinal, a identidade brasileira tornou-se, mais uma vez, refém dos afetos mais tristes, reativos e fascistas de uma população de classe média que se considera elite, o retorno do recalcado colonial. 
Todavia, essa primeira impressão é enganosa, pois não só Goddard não busca qualquer identidade, mas, ao contrário, a diferOnça, aquela diferença que vai além da discreta distinção (por exemplo, entre ele e Bento de Espinosa),como também nessa diferença de pontos de vista é a própria percepção que se altera, entrando em devir.E a percepção, assim como sua alteração, são criações, instauram um Perspectivismo - sob o qual nos debruçamos agora, como quem dobra a dobra e faz o avesso do avesso.

Se a filosofia na cartografia de Deleuze e Guattari (1992) necessita inventar personagens conceituais, que são os verdadeiros autores ou heterônimos do autor em devir criativo, personagens que por sua vez criam conceitos, que povoam um plano de imanência traçado para enfrentar o caos, Goddard traça um plano de imanência intensivo onde a brasilidade torna-se não um território, mas uma linha de desterritorialização de qualquer mesmo ou idêntico, que afronta o caos de pensamento europeu colonialista, que só sabe criar e consumir objetos-mercadorias, cego e surdo às forças, aos corpos vivos e aos espíritos.

Diante da sombra do fascismo carnavalizante verde-e-amarelo, retomar a brasilidade pela sua diferença, pelo seu caráter estrangeiro, inclusive e principalmente a nós, brasileiros, veio em boa hora. E, afinal, tal como Oswald de Andrade que conheceu o Brasil em Paris, quando, pela distância de perspectiva, pode enxergar distintamente nossa antropofagia, podemos nos valer de outros estrangeiros (independentemente de serem gringos) para nos auxiliar a ver o que, justamente por estar tão à mão, menos de um palmo à frente do nariz, não conseguimos tocar, enxergar ou sequer sentir no frio da madrugada fascista tupiniquim. Mas, para nadar no mar intempestivo desse livro, cumpre trazer alguns avisos aos aventureiros - ou então, traçar um litoral, um cais mais ou menos familiar, para nos sustentar na contemplação e nos preparar para a viagem.

Ainda na bela e não convencional apresentação do livro, o antropólogo do perspectivismo ameríndio, Viveiros de Castro, um dos deglutidos no ensaio de Goddard, resume este como uma filosofia nua que assume radicalmente a proposta contracanibal de pensar com o Brasil e não de interpretá-lo, ou falar sobre ele - como se o Brasil devorasse os estrangeiros que aqui aportaram para aclarar e ilustrar as terras tupiniquins. Filosofia nua contra canibal que se presta a desexplicar o Brasil através de uma leitura pelo avesso, ácida com os antropólogos e filósofos europeus, 
especialmente os de linha francesa, tão agraciados no mundo ocidental.

No entanto, o Brasil de Oswald,Catatau e Guimarães Rosa referências locais de desexplicação do Brasil - é demasiado incerto.E as certezas que os gringos vêm garimpar acabam extraindo deles sua seiva. Se estrangeiros vêm montar ou provar suas teorias por aqui, estas e não raro seus autores são atravessados por algo de incomensurável, que não cabe nas suas grades explicativas.

Isso porque a matéria prima intensiva, matéria informal que foi batizada pelos gringos de Brasil, é indomesticável. Talvez por isso nossa visão brasileira sobre o Brasil acabe por ser tão estática, tão congelada nos conceitos mortos que tomamos dos nossos colonizadores e seus saberes sedentários. Não conseguimos enxergar no Brasil muito pouco aquém ou além das grades da colonização, da imagem de um país colonizado, que teve sua população indígena massacrada, sua natureza explorada, que matou, torturou e escravizou milhões de africanos, cuja Europa e, depois, os EUA, explorou tudo o que podia, nos deixando na triste situação econômico-política de uma dependência.

À esquerda ou à direita, só vemos no Brasil uma triste colônia, que deve ser resolvida, à esquerda, por uma mudança social, econômica e política bem socialista ou desenvolvimentista e socialmente solidária, ou, à direita, por um alinhamento submisso e hipócrita aos interesses das nações que nos exploram, para nos desenvolvermos à sombra dos que entendem de potência técnica, científica e mercadológica. À esquerda ou à direita, nós, brazucas, só vemos a saída via a lógica e imaginação do colonizador, que, agora, se globalizou. "Agora, o mundo todo é global", isto é, ocidental, europeu, colonizador-colonizado. E não há nada mais triste do que uma imaginação colonizada, capaz de sonhar apenas o que já está previsto.

Nesse sentido, o manifesto de Goddard não deixa de ser um tapa na cara na imaginação colonial dos acadêmicos brazucas - para nos acordar para nossa tarefa, nós que só sonhamos com o mundo branco.Redescubram a brasilidade que vai além do Brasil!, seria um dos chamados que essa obra provoca em nosso espírito brazuca que só nos advém nos pesadelos ou sonhos mais estrangeiros.

O livro tem como articulador interlocutor e máscara do autor - o filósofo Baruch Spinoza. Spinoza sonha com um brasileiro negão e sebento - seria Bento? Sê-bento? - e, como que engolido pela visão de seu alter-brasílico, entra numa conversa com Goddard feito Pyaguachu 
(por seu mergulho no labirinto da brasilidade) sobre os desdobramentos, as consequências do imbróglio da circunstancial visão em seu quarto frio para pensar o mundo e o pensamento pelas vias brasileiras.

O Brasil que deglute Deleuze e Spinoza, assim como Viveiros de Castro, e mais que ele Davi Kopenawa, abocanha Clastres para levar a ciência de LéviStrauss de volta à floresta e a filosofia, às árvores.Não se trata mais da hierarquia do pensamento arborescente ou da matéria enraizada, tampouco do fundamento em alguma unidade superior ou de estruturas de ligações preestabelecidas. A floresta Yanomami não se presta à explicação topológica ou à sistematização do conteúdo acumulado com interpretações por comparação ou ramificação num único e robusto tronco capaz, por sua vez, de revelar a grande árvore do conhecimento como em Mil Platôs (Deleuze; Guattari, 1995a).

Se a contra-antropologia de Kopenawaem A queda do céu: palavras de um xamã yanomami,busca subverter a relação assimétrica entre a civilização mercadológica ocidental com seu olhar antropológico a partir de uma crítica articulada de um ponto de vista exclusivamente amazônico (Kopenawa; Albert, 2015), da perspectiva da floresta,
Goddard (2017a, p. 36) escreve como francês livresco engolido pela sua própria vertigem pelo Brasil: "a viagem é intensiva". E esse aspecto intensivo, típico de nossa história que, como toda história, tem um princípio ou proveniência (seja real, simbolizado ou imaginado) encontra nos indígenas o seu princípio de explicação, mas não só, dado que, nesse campo rizomático de desterritorialização, o tempo parece correr ao contrário.

Isto é, seria só depois de tudo o que nos aconteceu nesses séculos que podemos apreender a imanência brasileira, que tudo conecta, como sua Natureza naturante, incorrigivelmente em movimento, com fome de diferenças, que, por ser pura ação, não tem origem nem fim em seu processo de diferenciação. As indomáveis derivas da brasilidade são tão impossíveis quanto insuportáveis para as galimatias das empreitadas civilizatórias, feitas personagem conceitual Galli Mathias do discurso verborrágico e hermético acidamente devorados na antropofagia oswaldiana.

A epopeia da origem, dos descobridores e fundadores é suporte para a promessa contida do país do futuro. E embora ela caiba no Brasil, as brasilidades não cabem nestes sonhos imperiais. Bispo Sardinha que o diga, de dentro do caldeirão do Brasil. Não importa o futuro ou o 
passado nessa viagem, mas sim o meio onde o Brasil resiste e insiste. Mas onde? No corpo. Pois o Brasil, como abstração unificante, não existe.Tudo o que há é seucorpo, indócil de brasilidades. Nosso corpo, que não se distingue do espírito.Uma descoberta de Bento, cartesiano herético, que funde as três substâncias de Descartes, Deus, eu e mundo, em uma única substância imanente - Deus ou Natureza -, uma produção absoluta e infinita em seus modos, abrindo as portas do impossível para todas as misturas, produções de possíveis e diferenças.

Espinosa, contudo, ainda é mui cartesiano e mui europeu demasiadamente Galli Mathias para a antropofagia -, com seu latim medieval escolástico e suas lutas conceituais com Descartes e o monótonoteísmo judaicocristão. Mas seu alter-ego, Bento, o índio, ou Benedito, o negro, desvirtuam o Benedictus latino e o Baruch hebreu em uma linha de fuga herética do Velho Mundo. Benedito "Sê-Bento", bendito sebento, o duplo ou imagem no espelho da diferença de Espinosa, marrano que se descobre pensando em português, sua língua materna, personagem conceitual que cria esse plano de imanência antropofágico, onde os conceitos europeus e franceses são deglutidos e recriados - virados do avesso, não sem antes serem mortos com um único e forte golpe de tacape e suas histórias serem cozinhadas com muito molho e vegetais tropicais.

Os exemplos desse cozidão antropofágico no escrito de Goddard são inúmeros, tais como a literatura brasileira comida por ele, Clarice com seu olhoclitorispector, Leminski e seu Cartesius tropical, o ser-tão de Guimarães, as lutas de Glauber e seu real de Rocha viva.

\section{É possível ler Brazuca negão e} sebento como um exercício de decolonialidade à medida em que ele trabalha na fronteira das duas faces do conhecimento ocidental. Como crítica à colonialidade, inerente à modernidade ocidental - a qual opera através do menosprezo dos povos originários nãoeuropeus e a subsequente violência contra eles, que aparece sob as mais variadas formas: epistemicídio, colonialismo, escravização, genocídio e racismo (Mignolo, 2003).

Como avesso do narcisismo e do introspectivismo da antropologia urbanizada que conhece o mundo pelos livros e cujos autores, pondera Godard (2017b) em outro momento, escrevem porque não vivem e se põem a escrever acerca dos que não escrevem ignorando as palavras e distantes das pessoas e dos lugares outros. Ali, “onde o solitário, o 
melancólico europeu fraco em existência e em mundo reata-se às matilhas heterogêneas do Brasil" (Godard, 2017a, p. 29) é onde certa visão de mundo e Brasil é colocada na berlinda, ali onde ela eclode e em abertura que a faz tragada pela experimentação da bordura cosmogônica ao chegar no litoral.

Eles,europeus, não sabem mais sonhar com nada além deles mesmos. Por isso, é necessário tomar o "pesadelo" de Baruch (nome hebreu do marrano Espinosa) como um sonho de uma nova imagem de pensamento. Como diria Viveiros de Castro, inspirado pelos índios: o onirismo da figura contra o onanismo do conceito. Nada mais Espinosista, mas só de quem leu Espinosa com Oswald de Andrade, Deleuze, Davi Kopenawa, Artaud, Fichte e Viveiros de Castro.

Para pensar em terceiro gênero, considerando que é pensar pela potência de Deus ou da Natureza, é preciso pensar através dos corpos, isto é, por imagens, mas que deixam de serem discretas e separadas, identidades, para serem contínuas, produtivas e metamórficas, justamente porque não são simples imagens, mas ações, práticas. Não o teatro, grego, alemão ou francês, e sua imaginação sedentarizada, mas $\operatorname{sim}$ a floresta em criação, usina de produção nômade, onde nenhum corpo nasce e morre sozinho, onde a vida é teia de produção e criação em movimento.

E o que faz o francês trans-feitiçado Pyaguachu com este ensaio pantofágico, que se inspira na visão de um Espinosa brazuca, negão e sebento?

Em estado de estupefação criativa, Pyaguachu divaga furiosa, alternada e simultaneamente entre obra intelectual e biografia dos europeus canibalizados em suas tentativas de chegar ao Brasil. Desta forma, entre "anedota da vida e aforismo do pensamento" (Deleuze, 2000), o livro aborda questões sérias da política do conhecimento (seria filosofia?) ocidental, fazendo o Duplo desta mesma seriedade, carrancuda e embranquecida.

Como o avesso do avesso, Godard vê o outro em nós. Rebeldia à revelia, assim como Espinosa (que se quer Spinoza) alucina um Brazuca na Holanda, tão gelidamente e sensivelmente distante como o quarto frio em que Lévi-Strauss se põe a descrever e destrinchar as estruturas elementares do parentesco e da cozinha dos povos ameríndios sem se lambuzar na floresta, sem ouvir os xapiris.

Abocanhando os europeus para fazer filosofia, política epistemológica e ontologia pragmática através de uma etnografia do caos chamado Brasil, ou do cais onde se perfaz um Brasil virtual - o Brasil, país do futuronas palavras de 
Zweig, outro europeu devorado em terra tupiniquim.

Pois, para inventar o cais (o porto seguro da filosofia), há de se inventar o mar - na letra de Milton e Bastos, tão citada no livro. Por um lado, a invenção do Brasil com seus marcos territoriais, suas fronteiras e seus discursos de moral e verdade é menos interessante e cabe aos aristocratas e à plutocracia presentes no Estado colonial brasileiro, na burocracia e na república, assim como na monarquia. Por outro, a brasilidade da síncope é a do baque do tambor e das árvores da floresta, dela depende a invenção do caos, do cais e do mar. Em apneia neste mar de brasilidade, o livro oferece um mergulho intensivo de onde o leitor sai com os olhos vermelhos, oscilando entre a sensação de ter visto o que não esperava e a certeza de que algo passou e alguma coisa acontece com o Brasil e ele não se deu conta.

Inspirado na Viagem intensiva oferecida por Goddard a Bento, por meio da alucinação noturna do príncipe da filosofia, Pyaguachu faz uma ode à brasilidade somente possível com um mergulho na intensidade calculadamente evitada por Lévi-Strauss, feita parcialmente por Clastres, mas no qual se lambuza Fatumbi, vestido de mulher, num terreiro qualquer.
De fato, o francês entra num deviríndio-negro no exercício de alcançar um pensamento a partir das brasilidades. Porque um pensamento da brasilidade é um pensar híbrido e hibridizante. Através dele, nada pode permanecer sob a lógica do mesmo, do igual, da entidade idem. Afinal, idêntico a quê? À imagem empalidecida do pensamento? Nadica de nada. O buraco é mais embaixo - na linguagem deboche-escrachada de Goddard -, ou seria Catesius, personagem deste outro híbrido, polacobrazuca, Leminski?

Aliás, o livro é repleto de elogios aos híbridos de Clarice Lispector e Pierre Fatumbi Verger. Não obstante, ele performa hibridismos também. A porta de entrada para as sínteses disjuntivas é a história não contada dos grandes autores. Seus duplos. Esse orifício é onde se erguem os fundamentos dos pensamentos de Lévi-Strauss e Deleuze - do qual nem Pierre Clastres escapa. Se Dina LéviStrauss e Fanny Deleuze são condições e pilares para a compreensão de Claude e Gilles, o devir-mulher desses autores, Heléne Clastres poderia apontar para a saída de uma lógica binária e petrificada de Pierre Clastres, por meio do nomadismo dos karai, os profetas indígenas, e sua busca da terra sem mal, onde só se pode sair do mesmo (o homem) pela mulher. 
Com esta estratégia, Pyaguachu faz do escracho a nova língua da filosofia em estado de choque tropical, o mesmo tomado por Lévi-Strauss quando da sua chegada ao Brasil - que antes mesmo de chegar, já concebia de antemão que não poderia se imiscuir demasiadamente.Neste mergulho, originária é menos o porto seguro para as caravelas de Cabral que a deglutição do Bispo Sardinha, a qual mostra aos portugueses e demais europeus com que tipo de forças eles estão lidando.

Desde Tristes trópicos, Claude sabe das duas estratégias humanas para enfrentar a alteridade e, na dúvida, se municia de ambas para colocar o Brasil nas grades da disciplina moderna, mantendo a brasilidade a uma distância segura, onde talvez pode vê-la se assegurando de não ser abocanhado por ela. Primeiro, reconhece a antropoemia, própria da cultura europeia, que consiste em expulsar o outro para o exterior, mantendo-o temporária ou definitivamente incontactáveis. Sua tecnologia consiste em abocanhar para em seguida vomitar, cuspir o outro tido como estranho e alheio a fim de impedir todo contato, diálogo e interação com ele e sua lógica, a antropofagia.

Entretanto, se Claude só pode ver na antropofagia um meio de neutralizar e mesmo de aproveitar utilitariamente temíveis forças alheias, metabolizando-as para fazer delas idênticas aos corpos que as ingerem, Oswald de Andrade (1976), por outro lado, vê na diferença, o que não é nosso, o único interesse, a única lei do mundo. A antropofagia oswaldiana contradiz a versão da antropofagia de LeviStrauss (1996, p. 414) - que não deixa de ser o canibalismo típico do mundo capitalista - aquilo que Oswald chama de baixa antropofagia, o materialismo vulgar que assimila o outro para torná-lo idêntico a si.

$\mathrm{Na}$ verdade, a alta antropofagia oriunda da cosmologia indígena que permeia a subjetivação brasileira como a base de nosso corpo e pensamento, ainda que violentada pelo colonialismo capitalista, não se apropria do outro para anulá-lo, mas para absorvê-lo e promover uma transformação, que não significa uma síntese, pois, por não ter fim, prescinde de qualquer dialética reconciliatória. $\mathrm{A}$ antropofagia, neste sentido, pode ser pensada, tal como em Deleuze e Guattari (1995b), como uma linha de desterritorialização, onde segue-se a diferença em seu movimento de força, composição e alegria. Não se reconcilia com o inimigo, mas o ingere, apropria-se dele, para se tornar mais forte (Rolnik, 2000, 2006).

A alta antropofagia das linhas de desterritorialização indomáveis das 
brasilidades faz o onanismo dos livros dos mitos ocidentais deslizar numa viagem pelos ritos da intensidade. Rituais de manipulação e de trabalho com intensidade.

Ritos de transmutação xamânicos, iorubás e ameríndios. Ritos de modulações intensivas. Ritos capazes de transmutar o que se deseja e a própria autoimagem - se é que se pode tratar de autoimagem, quando na insólita conversa de negociação diplomática dos modernos civilizadores e os demais coletivos da Terra, Galli Mathias passa a xaxar com voz de mulher quando é confrontado com a diferença plural irreconciliável (Goddard, 2017a, p. 76), irredutível a qualquer termo comum, o como-um que apazigua sua radical alteridade, sua inextrincável duplicidade e estranheza.

Ritos indiscerníveis à medida em que não cabem nas Mitológicas (LeviStrauss, 2004) nas estruturas escritas em cubículos gélidos do outro lado do mundo. Apressadamente racionalizado em seu discurso hermético, Claude tinha necessidade de encontrar parâmetros para desvendar o insondável da boca banguela da baía de Guanabara.

É para chegar até a brasilidade das frestas e das festas, dos ritos e dos gritos é que Goddard revira o fundo das malas dos franceses em suas vindas ao Brasil e em suas aventuras intelectuais para sair de lá com anti-conceitos que não cabem nas imagens que Lévi-Strauss carrega com os tópicos de seus Tristes Trópicos. As matilhas étnica e musicalmente antropófogas, multidões luso-indoafricanas, turbulentas, alegres e predadoras, não cabem na compreensão do deserto em que falta humanidade, tampouco se adequam à multidão fétida e miserável que lhe serve de modelo desde Calcutá para medir o Brasil.

Por isso, a pluralidade de tais multiplicidades, multitudinárias e ritualísticas, recebem o nome de diferonça. Um déjàguar infinitivo, devir-jaguar do perspectivismo próprio ao corpopensamento-devir ameríndio. $\mathrm{Ou}$, nos termos que nos cabem: desterritorialização da alta antropofagia.

Se isso faz sentido ainda hoje, pode-se dizer, tal como afirmam Deborah Danowski e Viveiros de Castro (2014), que, diante do colapso iminente, mas em processo, da modernidade capitalista, o mundo todo tornar-se-á indígena, isto é, sobreviverá em um mundo que acabou tal como os índios tiveram o seu mundo destruído pela chegada do planeta Mercadoriana América indígena, mas ainda sim sobrevivem.

Mesmo que dezenas de milhões tenham morrido, ainda assim o espírito 
indígena sobrevive, não apenas perseverando em seus costumes, tradições e modos de vida, mas acima de tudo absorvendo o inimigo que o cerca de todos os lados. Se os índios usam dos instrumentos do modo de vida ocidental (roupas, tecnologia, língua, política etc.) não é para deixarem se ser índios, mas, justamente, porque seu perspectivismo animista, de raiz antropofágica, enxerga que, se tudo é humano - e por isso perigoso, virtualmente um outro inimigo apropriar-se do outro e, assim, diferir, é uma estratégia de sobrevivência. Alta antropofagia que talvez seja o destino futuro do nosso mundo e a contribuição da brasilidade para uma redefinição do viver.

\section{Referências}

Andrade, O. (1976) O manifesto antropófago. In G. Teles. Vanguarda européia e modernismo brasileiro: apresentação e crítica dos principais manifestos vanguardistas (pp. 24-30). Petrópolis: Vozes;Brasília: INL.

Danowski, D.\& Viveiros de Castro, E. (2014) Há mundo por vir? Ensaio sobre os medos e os fins. Desterro, Florianópolis: Cultura e Barbárie: Instituto Socioambiental.

Deleuze, G. (2000). Lógica do Sentido. São Paulo: Perspectiva.

Deleuze, G.\& Guattari, F. (1992).O que é a filosofia?. Rio de janeiro: Ed. 34.
Deleuze, G.\& Guattari, F. (1995a). Mil platôs: capitalismo e esquizofrenia 2, vol. 1 Rio de janeiro: Ed. 34.

Deleuze, G.\&Guattari, F. (1995b). Mil Platôs: capitalismo e esquizofrenia 2, Vol. 2. Rio de Janeiro: Ed. 34.

Goddard, J. C. (2017a).Brazuca, negão e sebento. São Paulo: n-1 edições.

Goddard, J. C. (2017b).Idiotia branca e cosmocídio: uma leitura de $A$ queda do céu, de Davi Kopenawa e Bruce Albert. Revista de @ntropologia da UFSCar, 9(2) (suplemento), jul./dez. Recuperado de: http://www.rau.ufscar.br/wpcontent/uploads/2018/01/Suplemento28-37.pdf

Kopenawa, D. \&Albert, B. (2015).A queda do céu: palavras de um xamã yanomami. São Paulo: Companhia das Letras.

Levi-Strauss, C. (1996).Tristes trópicos. São Paulo: Companhia das Letras.

Levi-Strauss, C. (2004).O cru e o cozido. Mitológicas 1. São Paulo, CosacNaify.

Mignolo, W. (2003). Histórias locais/projetos globais: colonialidade, saberes subalternos e pensamento liminar. Belo Horizonte: Ed. UFMG.

Rolnik, S. (2006). Cartografia sentimental: transformações contemporâneas do desejo. Porto Alegre: Sulina; Editora da UFRGS.

Rolnik, S. (2000). Esquizoanálise e Antropofagia. In E. ALIEZ (Org.). Gilles Deleuze: uma vida filosófica (pp. 451 - 462). São Paulo: Editora 34. 
Guilherme Augusto Souza Prado é psicólogo pela Universidade Estadual Paulista, mestre e doutor em psicologia clínica e subjetividade pela Universidade Federal Fluminense com estágio de doutoramento na Universidad Complutense de Madrid. É também pesquisador de políticas de subjetivação, clínica ampliada em saúde e esquizoanálise. Coordenador NuTEPSS - Núcleo de Estudos e Pesquisas em Saúde e Subjetividade da UFDPar - PI.

Email: guispra@gmail.com

ORCID: http://orcid.org/0000-0001-93188580

Márcio José de Araújo Costa é psicanalista, bacharel e especialista em Filosofia. Psicólogo, Mestre e Doutor em Psicologia Social (UERJ). Possui pósdoutorado em Psicologia Clínica pela PUC-SP e pós-doutorando em Teoria Psicanalítica pela UFRJ. É também professor da graduação e do Programa de Pós-graduação em Psicologia da UFMA.

Email: marciojacosta144@gmail.com ORCID:https://orcid.org/0000-0002-8117$\underline{3389}$

Enviado em: 17/09/19- Aceito em: 09/07/20 